\title{
Comparison of Four Foraminiferal Biotic Indices Assessing the Environmental Quality of Coastal Mediterranean Soft Bottoms
}

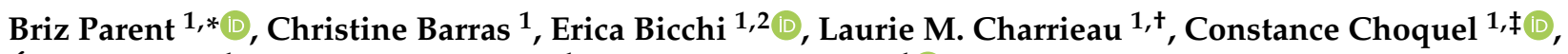 \\ Éric Bénéteau ${ }^{1}$, Grégoire M. Maillet ${ }^{1}$ and Frans J. Jorissen ${ }^{1}$ (D) \\ 1 UMR CNRS 6112 LPG-BIAF, Université d'Angers, 2 Boulevard Lavoisier, 49045 Angers CEDEX, France; \\ christine.barras@univ-angers.fr (C.B.); ebicchi@esaip.org (E.B.); laurie.charrieau@awi.de (L.M.C.); \\ constance.choquel@gmail.com (C.C.); eric.beneteau@univ-angers.fr (É.B.); \\ gregoire.maillet@univ-angers.fr (G.M.M.); frans.jorissen@univ-angers.fr (F.J.J.) \\ 2 Esaip La Salle, 18 rue du 8-mai-1945, 49180 St Barthélemy d'Anjou, France \\ * Correspondence: briz.parent@gmail.com \\ + Present address: Biosciences, Alfred Wegener Institute, Am Handelshafen 12, 27570 Bremerhaven, Germany. \\ $\ddagger$ Present address: Department of Geology, Lund University, Sölvegatan 12, 22362 Lund, Sweden.
}

Citation: Parent, B.; Barras, C.; Bicchi, E.; Charrieau, L.M.; Choquel, C.; Bénéteau, É.; Maillet, G.M.; Jorissen, F.J. Comparison of Four Foraminiferal Biotic Indices Assessing the Environmental Quality of Coastal Mediterranean Soft Bottoms. Water 2021, 13, 3193. https://doi.org/10.3390/w13223193

Academic Editors: Vincent Bouchet, Fabrizio Frontalini and

Daniela Zeppilli

Received: 9 September 2021

Accepted: 9 November 2021

Published: 11 November 2021

Publisher's Note: MDPI stays neutral with regard to jurisdictional claims in published maps and institutional affiliations.

Copyright: (c) 2021 by the authors. Licensee MDPI, Basel, Switzerland. This article is an open access article distributed under the terms and conditions of the Creative Commons Attribution (CC BY) license (https:// creativecommons.org/licenses/by/ $4.0 /)$.

\begin{abstract}
Coastal environments are exposed to numerous pressures that potentially affect marine soft bottom faunas. Among these pressures, organic matter enrichment is very frequent. Several indices based on living (Rose Bengal-stained) foraminiferal communities have recently been developed to assess the induced impact and determine the environmental quality of these environments. Here, we use an open waters Mediterranean Sea data set to test the benefits and drawbacks of four foraminiferal indices: (1) the effective number of species $\left(\exp \left(\mathrm{H}_{\mathrm{bc}}^{\prime}\right)\right),(2)$ the Tolerant Species Index for the Mediterranean (TSI-Med), (3) the Foraminifera AMBI (Foram-AMBI), and (4) the Foram Stress Index (FSI). These indices all intend to measure the response of the foraminiferal communities to organic matter enrichment, and therefore, their results should be very similar. We found that the diversity-based index, $\exp \left(\mathrm{H}_{\mathrm{bc}}^{\prime}\right)$, was not suitable to evaluate the environmental quality of our Mediterranean coastal settings, as it had a non-monotonic relationship with the organic matter enrichment gradient. The three indices based on groups of indicator species (TSI-Med, Foram-AMBI, and FSI) yielded fairly similar results. For Foram-AMBI, using only assigned species to calculate proportions of indicator species partly avoided to misinterpret the results. In TSI-Med, a correction based on sediment grain size is applied to distinguish between natural and anthropogenic organic enrichment. Such a correction could also be added to Foram-AMBI and FSI. The limits between the Ecological Quality Status (EQS) classes used for macrofauna were not adapted for Foram-AMBI. Here, we propose new EQS class limits for the Foram-AMBI as follows: very good: $0 \leq \mathrm{x}<1.4$; good: $1.4 \leq \mathrm{x}<2.4$; moderate: $2.4 \leq \mathrm{x}<3.4$; poor: $3.4 \leq \mathrm{x}<4.4$; bad: $4.4 \leq \mathrm{x} \leq 6$. These limits could evolve in the future as new data become available, especially with a poor and bad environmental quality.
\end{abstract}

Keywords: biomonitoring; TSI-Med; Foram-AMBI; FSI; effective number of species; organic matter enrichment; Ecological Quality Status

\section{Introduction}

Anthropogenic pressures strongly impact coastal environments, in particular marine soft-bottom ecosystems. Benthic communities living in these habitats respond to the chemical (e.g., organic input, nutrients, heavy metal contamination) and/or physical (e.g., trawling, dumping of dredging residues) pressures induced by human activities [1-5]. In the case of organic matter enrichment and associated oxygen depletion, this response results in successions of different benthic communities along the pressure gradient [6-10]. Based on this paradigm, various biotic indices using macrofaunal benthic communities have been developed, allowing to quantitatively assess the ecological quality of the concerned environments (e.g., [11-15]). 
In recent years, benthic foraminifera have been increasingly used in biomonitoring studies, because of their high density, diversity, and ubiquity, their short life span, and also the potential conservation of their tests in the sediment archive, offering the possibility to assess past environmental baseline conditions (e.g., [16-18]). Consequently, several indices based on living foraminiferal faunas have been developed [19]. These indices, which are all based on faunal successions along stress gradients, use slightly different approaches. The majority uses indicator taxa, either based on stress-tolerant species or stress-sensitive ones. Other approaches use diversity measurements.

As the available indices increase, their performances need to be compared to determine their strong and weak aspects. In this study, we compare four different foraminiferal indices developed in the Mediterranean Sea, by applying them on a large data set from the French Mediterranean coast. The three indices based on indicator species groups have all been implemented in the Mediterranean Sea: the Tolerant Species Index (TSI-Med) [20], the AZTI's Marine Biotic Index based on Foraminifera (Foram-AMBI) [21,22], and the Foram Stress Index (FSI) [23]. As diversity index, we tested the $\exp \left(\mathrm{H}^{\prime}{ }_{\mathrm{bc}}\right)$, which is a measure of the effective number of species [24,25].

The three indices using indicator species are all based on the relative proportions in the fauna of several groups of indicator taxa. They differ in three main aspects: (1) the types of indicator taxa used (i.e., stress-sensitive and/or stress-tolerant, opportunistic species, and the number of classes considered), (2) the relative weight given to each group of indicator taxa in the calculation of the index value, and (3) the addition or not of a correction for the natural trophic state. In TSI-Med and Foram-AMBI, the index value is mainly based on groups of stress-tolerant/opportunistic taxa. However, TSI-Med is based on a single group of stress-tolerant taxa, whereas Foram-AMBI distinguishes five different ecological groups (sensitive, indifferent, and three levels of opportunistic behaviour). The FSI subdivides the fauna in stress-sensitive and stress-tolerant taxa and uses the relative proportions of these two groups to calculate the index value, attributing ten times more weight to the first group. Only TSI-Med attempts to correct for the natural trophic state. These three biotic indices all intend to assess the environmental response to organic matter enrichment and should therefore lead to similar conclusions.

The diversity measure $\exp \left(\mathrm{H}_{\mathrm{bc}}^{\prime}\right)$ tested here was used for the first time for foraminiferal faunas in Norwegian fjords [26], where it showed a strong correlation with bottom-water dissolved oxygen concentration, but a weaker relationship with organic matter enrichment. Recently, it was also applied to Mediterranean foraminiferal communities in lagoons [27] and coastal areas [28].

The three indices based on indicator species groups were developed in different areas in the Mediterranean Sea: the French Mediterranean coast for TSI-Med, Elefsis Bay and Saronikos Gulf in the Aegean Sea, near Athens, for FSI, and various open-water areas in the Mediterranean for Foram-AMBI: mostly the Italian coasts (especially Adriatic Sea), the Levantine basin, and the French coast. The publications introducing these three indices $[20,21,23]$ all present lists of species assigned to the different ecological groups. Unfortunately, there are more or less important differences between the species assignments. This is due to regional faunal differences, but probably also to the fact that two different methods were used: in TSI-Med and FSI, species assignments are based on a general literature review, whereas in Foram-AMBI these assignments are based on a detailed analysis of the species response to organic matter enrichment described in 15 previous studies from the Mediterranean (see Jorissen et al. [21] for details).

In principle, a biotic index is expected to express the environmental quality of sampling sites in a quantitative way. The definition of a number of Ecological Quality Status (EQS) classes (usually five, grading from "very good", "good", "moderate", "poor" to "bad"), and especially of the limits between these EQS classes, is crucial, as it allows to transform ecological quality measurements (the index values) into environmental quality labels [29]. These limits are especially important for policy makers and environmental management structures. However, it is difficult to find objective criteria to define these limits, and 
therefore the definition of EQS limits and the intercalibration of different indices remains an important issue $[14,17,27,30]$.

The four foraminiferal indices briefly presented above were tested in several studies (e.g., [28,31-34]). However, not all four indices and not all of their aspects (i.e., type, calculation, correction for the natural trophic state) were compared at the same time. In this study, we compare for the first time these four indices by applying them to a 38 stations sample set along the French Mediterranean coast, with contrasting sea floor characteristics, representing 147 samples. Our main aims were: (1) to test the differences in both approaches (i.e., indices based on groups of indicator taxa and on diversity); (2) to test the influence of the index calculations, by using the same ecological assignments of indicator taxa for each index; (3) to test the feasibility of a correction for the natural trophic state; and (4) to consider how EQS limits could be defined more objectively for the four studied biotic indices.

\section{Materials and Methods}

\subsection{Sampling, and Processing of Samples and Data}

Stations were sampled along the French Mediterranean coast during two surveys in spring (March-April) 2012 and 2015, onboard the RV Europe (Figure 1, Table S1). Among the 38 stations, 26 were sampled in both years. Sampling was performed with a Reineck box-corer, which was sub-cored with a tube of $7.4 \mathrm{~cm}$ inner diameter. The first centimetre of each sub-core was sliced off, preserved, and stained in a solution of $2 \mathrm{~g} \cdot \mathrm{L}^{-1}$ Rose Bengal in $96 \%$ ethanol for foraminiferal analyses. At each station, triplicate samples (three box-corer launches) were taken. At the laboratory, samples were washed through 63, 125, 150, and $500 \mu \mathrm{m}$ sieves. All stained (Rose Bengal) foraminifera from both size fractions between 125 and $500 \mu \mathrm{m}$ were wet-picked under a stereomicroscope, stored in micropaleontological slides, and specimens were identified to the species level. The $125-500 \mu \mathrm{m}$ fraction was studied to follow the recommendations of the FOBIMO expert group for bio-monitoring studies [35]. Foraminifera from sandy samples of the 2015 survey were concentrated using a solution of sodium polytungstate at a density of 2.3 [36]. To limit the bias due to low total abundances, only samples with 50 or more individuals were considered in this study.

In addition, onboard, the remaining surface sediment $(0-1 \mathrm{~cm})$ of the first box-corer launch (i.e., replicate "a") was used for grain size analysis. If the sediment appeared visually different in the second and third launches (i.e., replicates " $b$ " and " $c$ "), another sample was taken for grain size analysis. At the laboratory, for the 2012 samples, the sediment was dry-weighted and sieved on $63,125,150,250$, and $500 \mu \mathrm{m}$ meshes. Then, the percentage of the total dry weight was calculated for each size fraction. For the 2015 samples, three aliquots of each sample were homogenised with a shaker at $17 \mathrm{~Hz}$ for $3 \mathrm{~min}$. Then, aliquots were sieved on a $2 \mathrm{~mm}$ mesh and analysed with a Malvern Mastersizer 3000 for grain size analysis. Three measures were performed for each aliquot. The most representative measure, i.e., presenting median values compared to all measurements, was then selected. The study area represents a wide range of environments, from muddy bottoms in the Gulf of Lion to coarse sands with shell debris more to the east. Some stations showed high quantities of large organic matter debris, mostly macroalgae and seagrass remains [20].

Relative frequencies were calculated for all foraminiferal species. The three replicate samples were treated independently throughout the study. All data transformations and statistical analyses were performed using R v4.0.5 [37]. The Spearman rho's coefficients were calculated using the $\mathrm{R}$ package pspearman $\mathrm{v} 0.3-0$ [38].

\subsection{Biotic Indices Based on Diversity}

Since biodiversity is expected to decrease with increasing eutrophication $[6,39,40]$, and diversity indices are incorporated in several multimetric macrofaunal indices, we decided to compare our indicator-species based indices with the biodiversity index $\exp \left(\mathrm{H}_{\mathrm{bc}}^{\prime}\right)$, which is a measure of the effective number of species present in a sample. This index is derived 
from the exponential of the Shannon entropy $\left(\mathrm{N} 1=\exp \left(\mathrm{H}^{\prime}\right)\right)$ [24], where the Shannon entropy $\left(\mathrm{H}^{\prime}\right)$ [41] is bias-controlled for unobserved species $\left(\mathrm{H}_{\mathrm{bc}}^{\prime}\right)$ [25]. Therefore, $\exp \left(\mathrm{H}_{\mathrm{bc}}^{\prime}\right)$ expresses the number of species that would be found in the sample if the species evenness was equal to 1 . The index only takes the relative abundances of all species into account; no assumptions are made concerning the relationship between individual species and trophic state. The bias-controlled entropy $\left(\mathrm{H}_{\mathrm{bc}}^{\prime}\right)$ was calculated using the $\mathrm{R}$ package entropy v1.2.1 [42], where it's exponential $\left(\exp \left(\mathrm{H}_{\mathrm{bc}}^{\prime}\right)=\mathrm{e}^{\mathrm{H} / \mathrm{bc}}\right)$ is the effective number of species.

\subsection{Biotic Indices Based on Groups of Indicator Species}

\subsubsection{Index Calculations}

We compared three biotic indices based on groups of indicator species. First, the Tolerant Species Index for the Mediterranean (TSI-Med) [20] is based on the percentage of stress-tolerant species in the sample $\left(\% \mathrm{TS}_{\mathrm{x}}\right)$, where species tolerant to eutrophication and/or hypoxia have been selected on the basis of a general literature review. A correction factor based on the percentage of sediment particles $<63 \mu \mathrm{m}$ is applied in order to take into account the natural trophic conditions at the station. In fact, organic matter is preferentially associated with the clay and silt fraction of the sediment [43,44], which generally leads to naturally higher organic carbon contents in fine-grained sediments, and consequently, higher percentages of stress-tolerant taxa [45]. This correction aims to avoid finding systematically lower ecological quality values for muddy stations, which are naturally rich in stress-tolerant taxa, than for sandy stations.

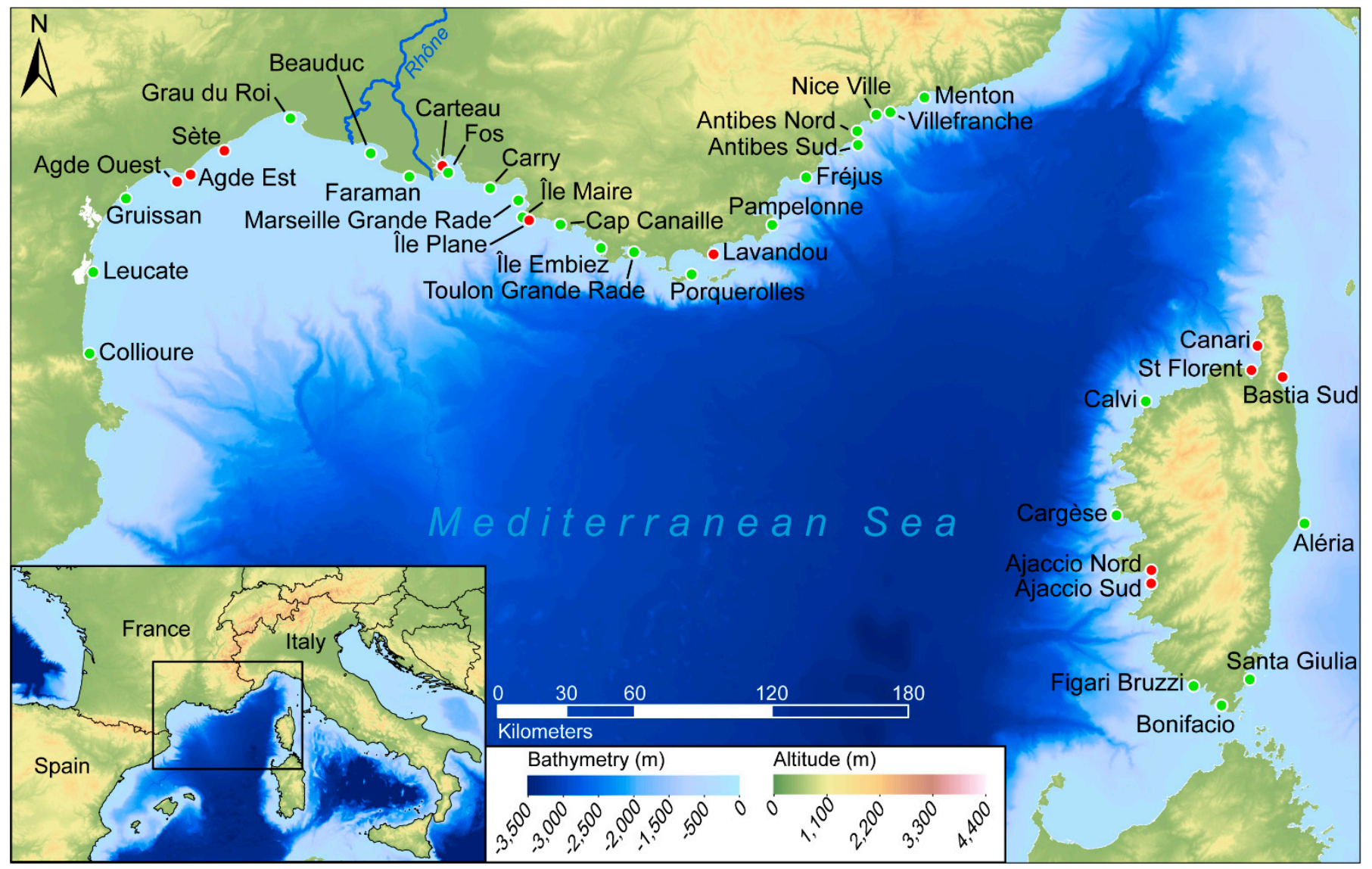

Figure 1. Sampled stations during the two surveys (2012 and 2015). The stations sampled during both surveys are in green, stations only sampled in 2012 or 2015 are in red. See Table S1 for details. Digital elevation models are from Jarvis et al. [46] and Marine Information Service [47].

The calculation of the TSI-Med follows three steps. First, the percentage of stresstolerant species in the fauna $\left(\% \mathrm{TS}_{\mathrm{x}}\right)$ is calculated (Equation (1)), taking into account all 
available taxa. Next, the reference percentage of tolerant species $\left(\% \mathrm{TS}_{\text {ref150 }}\right)$ is determined, in the function of the grain size of the sample (i.e., correction for the natural trophic state). Originally, \% $\mathrm{TS}_{\mathrm{ref} 150}$ was calculated on the basis of the percentage of stress-tolerant species present in the 150-500 $\mu \mathrm{m}$ fraction (Equation (1)), as described by Barras et al. [20]. However, the FOBIMO group recommends using the fraction $>125 \mu \mathrm{m}$ in biomonitoring studies [35] and consequently, we studied the $125-500 \mu \mathrm{m}$ fraction. Therefore, we had to reassess the reference curve for the $125-500 \mu \mathrm{m}$ fraction. Following the same methodology as Barras et al. [20] and using the 2012 dataset (excluding Corsica stations), we selected reference sites on the basis of a minimal percentage of stress-tolerant taxa (as observed in one of the three replicate samples) representing the whole range of grain sizes (from clayey to sandy substrates). A new reference curve for the fraction 125-500 $\mu \mathrm{m}$ was obtained by linearly regressing these reference points $\left(\% \mathrm{TS}_{\text {ref125 }}\right.$, Equation (2), Figure S2.1). When, in the second part of our comparison, we used a homogenised list of stress-tolerant species (following Jorissen et al. [21], see Section 2.3.2), we had again to reassess the reference curve for TSI-Med (\%TS ${ }_{\text {ref125homo, }}$ Equation (3), Figure S2.2). These equations are similar to the ones used by Parent et al. [34] in their study of the impact of sewage sludge on benthic foraminifera in the Eastern Mediterranean. Finally, the TSI-Med value is calculated on the basis of a comparison of $\% \mathrm{TS}_{\mathrm{x}}$ and $\% \mathrm{TS}_{\text {ref }}$ (Equation (4)). TSI-Med values range from about 0 (percentage of stress-tolerant taxa equal to the percentage under theoretical reference conditions, high environmental quality) to 100 (much more stress-tolerant taxa than expected under reference conditions, bad environmental quality). Exceptionally, when an individual $\% \mathrm{TS}_{\mathrm{x}}$ is lower than $\% \mathrm{TS}_{\text {ref }}$ (based on a regression of the lowest $\% \mathrm{TS}_{\mathrm{x}}$ ), the TSI-Med value can be slightly lower than 0 . Additional details on the TSI-Med calculation are presented by Parent et al. [34].

$$
\begin{gathered}
\% \mathrm{TS}_{\text {ref150 }}=\mathrm{e}^{0.0302 \times(\% \text { grains }<63 \mu \mathrm{m})+0.1496}-1 \\
\% \mathrm{TS}_{\text {ref125 }}=0.1547 \times(\% \text { grains }<63 \mu \mathrm{m})-0.3638 \\
\% \mathrm{TS}_{\text {ref125homo }}=0.3247 \times(\% \text { grains }<63 \mu \mathrm{m})-3.6718 \\
\mathrm{TSI}-\mathrm{Med}=\frac{\% \mathrm{TS}_{\mathrm{x}}-\% \mathrm{TS}_{\text {ref }}}{100-\% \mathrm{TS}_{\text {ref }}} \times 100
\end{gathered}
$$

The second index considered is Foram-AMBI $[21,22,48,49]$, derived from the AMBI index developed for macrofauna [11]. This index is based on the relative frequencies of five groups of indicator species (EGI to EGV, representing sensitive, indifferent, 3rd order opportunistic, 2nd order opportunistic, and 1st order opportunistic species, respectively). For the Mediterranean region, the species assignments to the five indicator groups [21] are based on a comparison of the distribution of the various species and sediment Total Organic Carbon (TOC) contents in 15 earlier Mediterranean studies. The Foram-AMBI is calculated as follows:

$$
\text { Foram }- \text { AMBI }=(0 \times \text { EGI })+(1.5 \times \text { EGII })+(3 \times \text { EGIII })+(4.5 \times \text { EGIV })+(6 \times \text { EGV })
$$

where EGI, EGII, EGIII, EGIV, and EGV represent the proportions of species assigned to each group. In Foram-AMBI, unassigned species are excluded from the data set before proportions are calculated $[11,50]$, so that the proportions of the five indicator groups sum up to 1. Values of Foram-AMBI range from 0 (100\% species of EGI) to $6(100 \%$ species of EGV); samples without living fauna are given a value of 7 .

The third index based on indicator species, the Foram Stress Index (FSI) [23], divides the fauna into two ecological groups, of stress-sensitive and stress-tolerant species. The attribution of the taxa to these two groups is based on literature evidence. In the case of taxa for which no ecological evidence is available, the assignment may be based on 
multivariate statistical analysis (Triantaphyllou M. V. and Hallock P., pers. comm. [51,52]). The FSI value is then defined as:

$$
\mathrm{FSI}=(10 \times \operatorname{Sen})+(\mathrm{Str})
$$

where Sen represents the proportion of stress-sensitive species, and Str represents the proportion of stress-tolerant species. The index value is largely determined by the proportion of stress-sensitive species. Contrary to TSI-Med and Foram-AMBI, the highest value of the FSI (10) corresponds to optimal environmental conditions whereas the lowest value (1) should correspond to highly deteriorated environments. A value of 0 is given to samples in which no living fauna is present. As it is defined, the FSI is more a measure of the absence of impact.

In the present study, the proportion of taxa that are not assigned by Dimiza et al. [23] to either stress-sensitive or stress-tolerant taxa was sometimes rather high. This problem concerned especially many agglutinated taxa with organic cement (e.g., Reophax, Trochammina, etc.). In order to respect, as much as possible, the method behind the index (i.e., considering all species, either as stress-tolerant or sensitive), we decided to exclude these unassigned taxa from the data set before recalculating species proportions (similar to the procedure followed in Foram-AMBI). Therefore, the sum of stress-sensitive and stress-tolerant species proportions remained equal to 1 . The lists of species assignments used in this study for the different indices are presented in Table S3.

To summarise, the main characteristics of these three indices are the strong contribution of the relative proportion of stress-tolerant species in the calculation of TSI-Med and Foram-AMBI, compared to the high contribution of stress-sensitive species in the calculation of FSI. Additionally, TSI-Med includes a correction for the natural trophic state, using sediment grain size. For a more general picture, Ecological Quality Status (EQS) classes were displayed for each of these indices, using the EQS limits proposed by the authors who developed the indices (Table 1). For each index, EQS limits were proposed specifically for foraminiferal fauna, except for the Foram-AMBI, for which at present only the EQS limits used for macrofauna are available.

Table 1. Limits of the EQS classes proposed for each foraminiferal index. NA: Not Assigned.

\begin{tabular}{cccccccc}
\hline Index & Very Good & Good & Moderate & Poor & Bad & Azoic & Reference \\
\hline $\exp \left(\mathrm{H}_{\mathrm{bc}}^{\prime}\right)$ & $\geq 10$ & $10 \geq \mathrm{x}>7.5$ & $7.5 \geq \mathrm{x}>5$ & $5 \geq \mathrm{x}>2.5$ & $>2.5$ & NA & Bouchet et al. [26] \\
TSI-Med & $\leq 4$ & $4 \leq \mathrm{x}<16$ & $16 \leq \mathrm{x}<36$ & $36 \leq \mathrm{x}<64$ & $64 \leq \mathrm{x} \leq 100$ & NA & Barras and \\
Foram-AMBI & $\leq 1.2$ & $1.2 \leq \mathrm{x}<3.3$ & $3.3 \leq \mathrm{x}<4.3$ & $4.3 \leq \mathrm{x}<5.5$ & $5.5 \leq \mathrm{x} \leq 6$ & 7 & Jorissen [53] \\
FSI & $\geq 9$ & $9 \geq \mathrm{x}>5.5$ & $5.5 \geq \mathrm{x}>2$ & & $2 \geq \mathrm{x} \geq 1$ & 0 & Dimiza et al. [54] \\
\hline
\end{tabular}

\subsubsection{Homogenised List of Indicator Species}

Among the biotic indices we compared, the three indices based on indicator species groups (TSI-Med, Foram-AMBI, FSI) not only differ in their calculation but also in the ecological assignments of their indicator taxa (Section 2.3.1 and Table 2); i.e., different number of EG and species assignment procedure to each EG. To distinguish between (1) the calculations underlying the three indices and (2) the effect of disparities in species assignments, we calculated the three indices twice. First, indices were calculated with the original species assignments (which show disparities for several species), and secondarily with the same species assignments for all three indices (the homogenised list), following the more objective assignments, specific for the Mediterranean open waters, proposed by Jorissen et al. [21]. 
Table 2. Groups of indicator species considered by TSI-Med, Foram-AMBI, and FSI indices, and equivalences considered in this study. Species groups that contribute most to the value of the biotic index are in bold.

\begin{tabular}{lccc}
\hline & TSI-Med & Foram-AMBI & FSI \\
\hline \multirow{2}{*}{ Assigned species } & Not Considered & Group I: sensitive & Stress-sensitive \\
\cline { 2 - 3 } & Stress-tolerant & Group II: indifferent & Not Considered \\
\cline { 2 - 3 } & & Group IV: 2nd order opportunist & Stress-tolerant \\
\cline { 3 - 4 } Unassigned species & Group V: 1st order opportunist & $\begin{array}{c}\text { In principle, all species are } \\
\text { assigned. In the present study, } \\
\text { they were excluded before } \\
\text { calculating percentages }\end{array}$ \\
\hline
\end{tabular}

It has been suggested that the reaction of a species to a stress factor could not be the same in different environmental settings or climates [55-59]. For this reason, the FOBIMO group proposed different lists of ecological species assignments for the north-eastern Atlantic [48], the Gulf of Mexico [49], European intertidal areas and transitional waters [22], and the Mediterranean Sea [21]. In our case, since all investigated samples came from the French Mediterranean coast, regional differences in species autecology should be minor or non-existent, and the use of the Mediterranean list of ecological species assignments appears justified.

For the homogenisation purpose, 1st, 2nd and 3rd order opportunists (as described by Jorissen et al. [21]) were grouped together in the stress-tolerant category when testing TSI-Med and FSI (Table 2). These "tolerant" and "opportunistic" species represent two contiguous fractions on the organic enrichment spectrum with a considerable overlap $[6,12,21,57,60-62]$. Since the two terms have been used interchangeably in the literature on biotic indices, and that it is difficult to distinguish between these two life strategies, we chose not to distinguish between opportunistic and stress-tolerant species for our aim is to compare index calculations.

\section{Results and Discussion}

\subsection{Effective Number of Species}

We started by comparing the effective number of species $\left(\exp \left(\mathrm{H}_{\mathrm{bc}}^{\prime}\right),[24,25]\right)$ with the three other indices (Figure 2). $\operatorname{Exp}\left(\mathrm{H}_{\mathrm{bc}}^{\prime}\right)$ shows weak but significant linear regressions with Foram-AMBI (negative, $\mathrm{R}^{2}=0.17, p$-value $<0.001$ ) and with FSI (positive, $\mathrm{R}^{2}=0.17$, $p$-values $<0.001$ ) but not with TSI-Med. In the case of Foram-AMBI and FSI, these models show that the effective species number tends to decrease towards sites with a lower environmental quality. However, in all three cases, the scatter is very important and the linear models never explain more than $17 \%$ of the total variability $\left(R^{2} \leq 0.17\right)$. As the absence of a strong linear relationship does not exclude a strong non-linear relationship between variables, we calculated Spearman's correlation coefficient (rho). This coefficient ranges from 1 , indicating a very strong positive monotonic relationship, to -1 , indicating a very strong negative monotonic relationship; values close to 0 indicate the absence of a monotonic relationship. In our case, the rho coefficients between $\exp \left(\mathrm{H}_{\mathrm{bc}}^{\prime}\right)$ and the three other indices were: -0.52 for Foram-AMBI $(n=147, p$-value $<0.001), 0.06$ for TSI-Med $(\mathrm{n}=147, p$-value $=0.444)$, and 0.49 for FSI $(\mathrm{n}=147, p$-value $<0.001)$. This shows weak monotonic relationships between $\exp \left(\mathrm{H}^{\prime}{ }_{\mathrm{bc}}\right)$ and Foram-AMBI (negative) and FSI (positive), and the absence of a monotonic relationship between $\exp \left(\mathrm{H}_{\mathrm{bc}}^{\prime}\right)$ and TSI-Med. In fact, for all three indices, a hump-shaped pattern can be seen, with the maximum effective number of species corresponding to intermediate values of TSI-Med, Foram-AMBI or FSI, whereas minimal values of $\exp \left(\mathrm{H}_{\mathrm{bc}}^{\prime}\right)$ correspond to extreme values of Foram-AMBI, TSI-Med and FSI, either high or low (i.e., good or bad environmental quality). 
a)

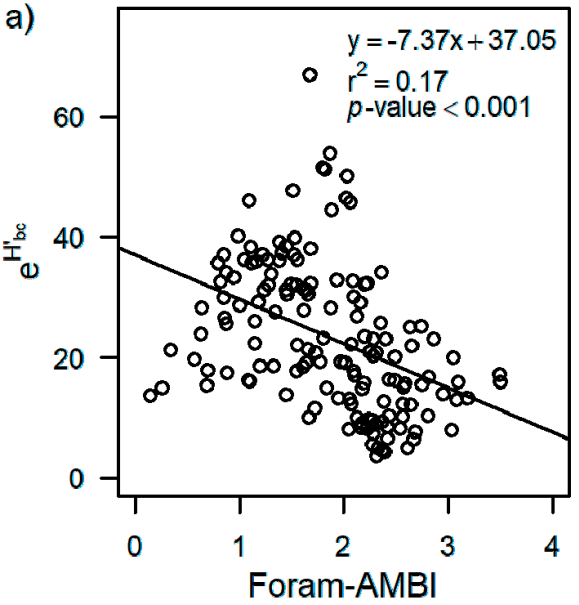

b)

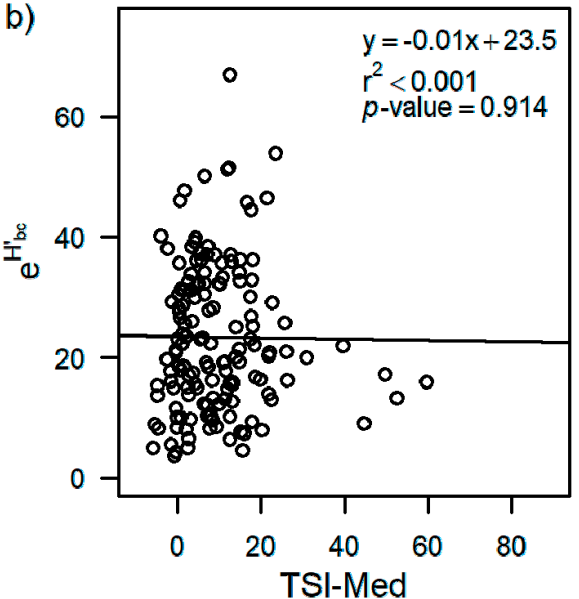

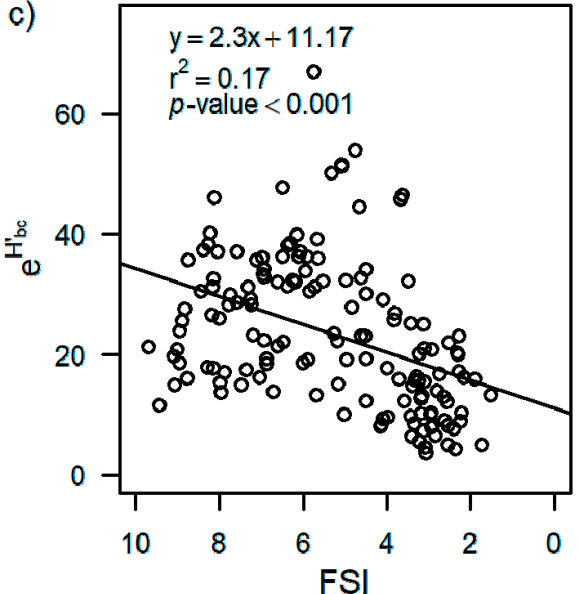

Figure 2. Values of the effective number of species $\left(\exp \left(\mathrm{H}_{\mathrm{bc}}^{\prime}\right)\right)$ compared to the values of the (a) Foram-AMBI, (b) TSI-Med, and (c) FSI for the 125-500 $\mu \mathrm{m}$ size fraction. The scale for FSI is reversed so that the environmental quality scale increases to the right for each index.

The $\exp \left(\mathrm{H}_{\mathrm{bc}}^{\prime}\right)$ of foraminiferal assemblages was first tested as an index of environmental quality in Norwegian fjords, where it was strongly correlated with bottom water $\left[\mathrm{O}_{2}\right]$ at the time of sampling, but showed a weaker correlation with TOC content or grain size [26]. Indices based on diversity and indices based on macrofaunal indicator taxa show discrepancies in Mediterranean transitional waters (lagoons and coastal lakes), whereas diversity indices based on foraminifera and on macrofauna show similar results [27]. Transitional environments (fjords and lagoons) are often highly impacted by multiple stressors, and the organic matter content is naturally higher than in open marine areas [19,22]. It appears that in these naturally organic enriched environments, only the lower part of the total overall environmental quality gradient could be present. In these organic enriched environments, there could indeed be a positive linear regression between $\exp \left(\mathrm{H}_{\mathrm{bc}}^{\prime}\right)$ and environmental quality [27]. In the much more oligotrophic Mediterranean open marine ecosystems tested here, a much wider range of environmental quality appears to exist, including the higher part of the trophic state gradient (i.e., lower organic matter content). In most oligotrophic ecosystems, an increase in organic matter input will lead to an increase in diversity $[6,40]$. Diversity will only start to decrease again when environmental stress surpasses a critical threshold value. Therefore, here the relationship between the biotic indices and $\exp \left(\mathrm{H}_{\mathrm{bc}}^{\prime}\right)$ is non-monotonic. Similar results were found by Subida et al. [63] for macrofauna in the Mediterranean. Because of the non-monotonic relationship between $\exp \left(\mathrm{H}_{\mathrm{bc}}^{\prime}\right)$ and environmental quality, it appears that $\exp \left(\mathrm{H}_{\mathrm{bc}}^{\prime}\right)$ is not a suitable index for our open marine Mediterranean environments, which are generally more oligotrophic than Norwegian fjords and Mediterranean lagoons. Consequently, we decided not to investigate this index any further.

\subsection{Comparing the Three Indices Based on Species Composition}

Despite having a similar approach (i.e., the use of EGs), the three biotic indices tested here have different methods (e.g., number of ecological groups considered, the process to assign species to different EGs). In the next section, we will study the impact of three aspects of these biotic indices methods: (1) the treatment of unassigned species, (2) the list of species, and (3) the EGs used by each index on the results of the three indices.

\subsubsection{Treatment of Unassigned Species}

In the case of a high percentage of unassigned species, Foram-AMBI and FSI, with all species assigned to EGs, become unreliable [14,64]. Consequently, for macrofaunal AMBI, two critical limits have been proposed: with less than $80 \%$ of the total fauna consisting of assigned species, the AMBI index should be interpreted with much care, and below a 
threshold of 50\% of assigned species, AMBI should not be calculated [64]. For TSI-Med, which uses only the percentage of stress-tolerant taxa, the non-assignation, even in large proportions, of species other than stress-tolerant is irrelevant.

When using the ecological species assignments of Jorissen et al. [21] in our data set, species unassigned to any ecological category account for $22 \pm 13 \%$. Of the 147 studied samples, 65 samples have less than $20 \%$ of unassigned species; 78 samples between 20 and $50 \%$ of unassigned species, and 4 samples more than $50 \%$. Among these unassigned species, 13 can be considered as major species (i.e., $>10 \%$ in at least one sample). Table 3 summarises the distributional data for these 13 species.

Table 3. Major species (i.e., at least present $>10 \%$ in one sample) unassigned by Jorissen et al. [21]. Total number of samples $=147$.

\begin{tabular}{|c|c|c|c|c|c|}
\hline Species & $\begin{array}{c}\text { Average }( \pm S D) \\
\text { Percentage in } \\
\text { All Samples }\end{array}$ & $\begin{array}{c}\text { Average }( \pm S D) \\
\text { Percentage } \\
\text { When Present }\end{array}$ & $\begin{array}{c}\text { Number of } \\
\text { Samples Where } \\
\text { Present }\end{array}$ & $\begin{array}{c}\text { Number of } \\
\text { Samples Where } \\
\text { Present }>1 \%\end{array}$ & $\begin{array}{c}\text { Number of } \\
\text { Samples Where } \\
\text { Present }>5 \%\end{array}$ \\
\hline Ammoscalaria pseudospiralis & $2.8 \pm 4.0$ & $5.0 \pm 4.1$ & 81 & 62 & 37 \\
\hline Ammoscalaria sp. 1 & $0.3 \pm 1.1$ & $1.3 \pm 2.0$ & 34 & 12 & 1 \\
\hline Ammoscalaria sp. 2 & $0.5 \pm 1.8$ & $2.4 \pm 3.2$ & 32 & 20 & 2 \\
\hline Cancris auriculus & $1.7 \pm 3.1$ & $3.2 \pm 3.8$ & 76 & 48 & 17 \\
\hline Fissurina orbignyana & $0.8 \pm 2.6$ & $2.8 \pm 4.2$ & 43 & 24 & 6 \\
\hline Haplophragmoides canariensis & $0.6 \pm 1.4$ & $1.3 \pm 1.8$ & 72 & 24 & 6 \\
\hline Hormosinella guttifera & $0.3 \pm 2.7$ & $9.9 \pm 12.5$ & 5 & 3 & 2 \\
\hline Lagena striata & $0.2 \pm 1.0$ & $0.8 \pm 1.7$ & 43 & 7 & 1 \\
\hline Nouria cf. polymorphinoides & $1.2 \pm 2.6$ & $2.8 \pm 3.3$ & 65 & 41 & 12 \\
\hline Quinqueloculina cf. laevigata & $0.2 \pm 1.1$ & $1.2 \pm 2.5$ & 23 & 4 & 1 \\
\hline Quinqueloculina sp. 1 & $0.2 \pm 1.2$ & $1.9 \pm 3.2$ & 16 & 7 & 1 \\
\hline Recurvoides sp. 1 & $1.8 \pm 5.7$ & $4.7 \pm 8.6$ & 56 & 35 & 13 \\
\hline Robertinoides bradyi & $0.2 \pm 1.1$ & $0.9 \pm 1.9$ & 39 & 7 & 1 \\
\hline
\end{tabular}

All these species have not been assigned by Jorissen et al. [21], because insufficient information was available. It is remarkable that 8 of these 13 major species are agglutinant taxa with an organic cement, with a test that will rapidly disintegrate after their death. Such non-fossilising agglutinants are only present in high-quality samples in which the sediment surface is sampled adequately (i.e., following the FOBIMO protocol). Their systematic lack in some of the 15 studies considered by Jorissen et al. [21] may be due to the use of thanatocoenoses (e.g., [65-67]). Additionally, some of these species may not have been recognised as alive in these earlier studies, because the stained protoplasm can only be seen easily, when the foraminifera are wet-picked, which was not the case for all studies.

It seems possible that some of the major unassigned species (e.g., Ammoscalaria pseudospiralis, and Cancris auriculus) have a life strategy typical of opportunistic and/or stresstolerant taxa. This would mean that at present when the species listing of Jorissen et al. [21] is used, the percentage of stress-tolerant species may be somewhat underestimated. Alternatively, among the less frequent taxa, many could be K-selected stress-sensitive taxa, which are characterised by low percentages (e.g., Lagena striata, and Robertinoides bradyi. Not considering these taxa will tend to overestimate the Foram-AMBI and to underestimate the FSI values.

Although this is beyond the aim of the present study, it appears essential that for all these taxa, reliable data become available, so that they can be assigned to ecological groups. At present, the average percentage of unassigned species is relatively high. The reliability of Foram-AMBI and FSI diminishes in samples with a high cumulative percentage of unassigned species. To avoid a misinterpretation of the ecological quality, the best strategy towards these unassigned taxa is to remove them from the dataset before the EG percentages calculation. The presence of unassigned species is only affecting TSIMed if stress-tolerant taxa are concerned. Since stress-tolerant taxa tend to be frequent in organically enriched ecosystems, as they often have an opportunistic behaviour, the chance 
that they cannot be assigned to an EG is low. This suggests that TSI-Med is less affected by unassigned species than the other two methods.

\subsubsection{Comparing the Indices Using Original Species Assignments}

Even when using the original ecological species assignments, which are different for the three tested indices based on groups of indicator taxa, the three indices are significantly correlated ( $p$-value $<0.001$ ) (Figure 3, Table 4). The coefficients of determination $\left(R^{2}\right)$ are 0.76 for FSI versus Foram-AMBI, 0.31 for Foram-AMBI versus TSI-Med, and 0.28 for FSI versus TSI-Med. As seen in the previous section, unassigned species may have a considerable impact on index reliability. We performed the same analyses only considering samples with less than $20 \%$ of unassigned species ( 65 samples out of 147). The results are very similar (Table S4) to what we obtain with all samples (Figure 3, Table 4). Therefore, we decided to keep on using all 147 samples. TSI-Med and Foram-AMBI show a majority of high ecological quality values, whereas the values are more equally distributed between bad, moderate, and good quality for FSI (Figure 3). Of course, this offset is largely due to the limits between the quality classes, as they have been determined originally. The systematic offset in ecological quality classes (EQS) between TSI-Med/Foram-AMBI and FSI strongly suggests that the limits between the five ecological quality classes should be reconsidered. This point will be treated in more detail in Section 3.4.
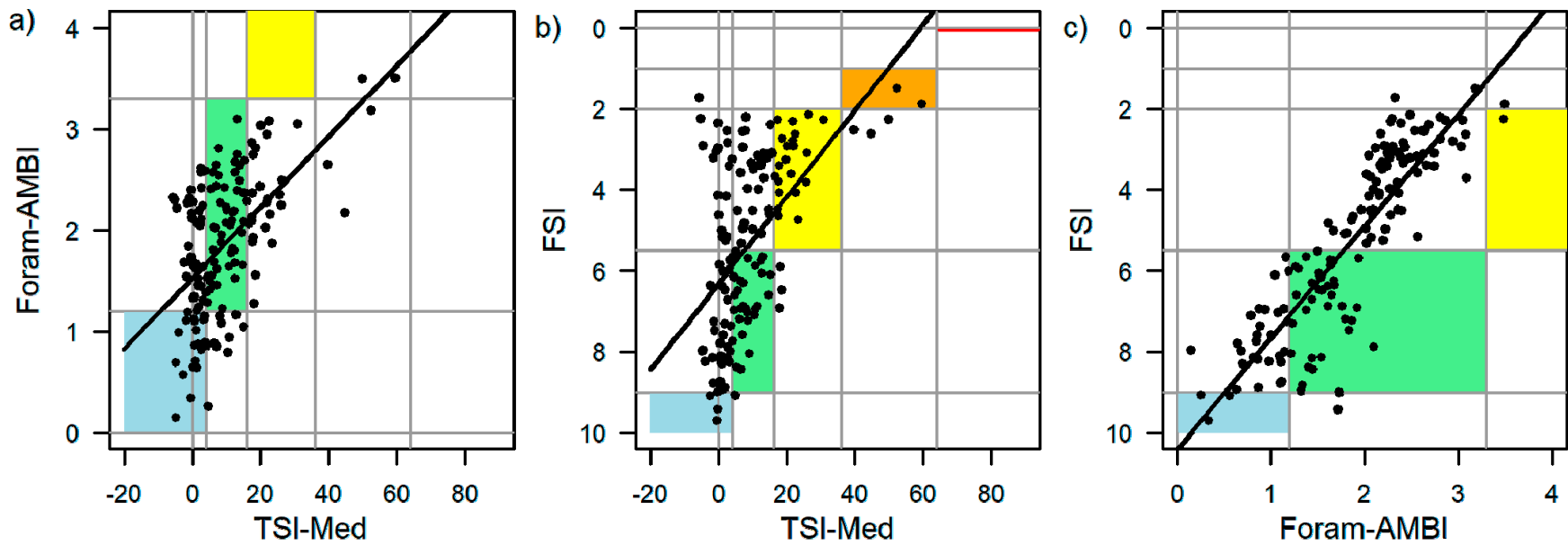

Figure 3. Quality indices based on groups of indicator species compared two by two. (a) Foram-AMBI vs. TSI-Med, (b) FSI vs. TSI-Med, (c) FSI vs. Foram-AMBI. Information on linear regressions is summarised in Table 4. For all comparisons, the original ecological assignments have been used. For FSI and Foram-AMBI percentages have been calculated after omitting unassigned taxa. The grey horizontal and vertical lines represent the Ecological Quality Status limits presented in Table 1. Coloured rectangles correspond to the areas were both indices have the same EQS: blue, "very good"; green, "good"; yellow, "moderate"; orange, "poor" and red, "bad". The scale for FSI is reverse so that the environmental quality scale is in the same direction for each index.

Since TSI-Med and Foram-AMBI are both largely based on the percentage of stresstolerant taxa, the rather poor fit is somewhat surprising (Figure 3a). This appears to be mainly the consequence of the very large scatter in Foram-AMBI for samples with high environmental quality. The coefficient of determination between TSI-Med and FSI is even weaker. In Figure $3 \mathrm{~b}$, we see that this low $\mathrm{R}^{2}(0.28)$ is largely due to the fact that samples with a low TSI-Med value (low percentage of stress-tolerant taxa, indicative of good quality) cover the whole range of FSI values. This implies that such samples have highly variable percentages of stress-sensitive taxa, which largely (for 91\%) determine the FSI value. On the contrary, the correlation coefficient between FSI and Foram-AMBI (Figure 3c) is much higher (0.69), probably because stress-sensitive taxa also contribute substantially to the Foram-AMBI value. 
Table 4. Summarised information on the simple linear regressions between the indices based on group of indicator species (Foram-AMBI, TSI-Med, and FSI).

\begin{tabular}{|c|c|c|c|c|c|c|}
\hline List of Species & $\begin{array}{l}\text { Correction For } \\
\text { Grain Size }\end{array}$ & Figure & Compared Indices & Equation & $\mathbf{R}^{2}$ & $p$-Value \\
\hline Original & \multirow{6}{*}{$\begin{array}{l}\text { Foram-AMBI and } \\
\text { FSI are not corrected } \\
\text { for grain size }\end{array}$} & Figure $3 a$ & Foram-AMBI vs. TSI-Med & $y=0.035 x+1.524$ & 0.31 & $<0.001$ \\
\hline species & & Figure $3 b$ & FSI vs. TSI-Med & $y=-0.107 x+6.307$ & 0.28 & $<0.001$ \\
\hline assignment & & Figure $3 c$ & FSI vs. Foram-AMBI & $y=-2.762 x+10.426$ & 0.76 & $<0.001$ \\
\hline \multirow{5}{*}{$\begin{array}{l}\text { Homogenised } \\
\text { list of } \\
\text { indicator species }\end{array}$} & & Figure $4 \mathrm{a}$ & Foram-AMBI vs. TSI-Med & $y=0.025 x+1.091$ & 0.57 & $<0.001$ \\
\hline & & Figure $4 b$ & FSI vs. TSI-Med & $y=-0.075 x+6.954$ & 0.58 & $<0.001$ \\
\hline & & Figure $4 c$ & FSI vs. Foram-AMBI & $y=-2.845 x+9.979$ & 0.94 & $<0.001$ \\
\hline & Grain size corrected & Figure $5 b$ & Foram-AMBI vs. TSI-Med & $y=0.032 x+0.132$ & 0.77 & $<0.001$ \\
\hline & Foram-AMBI and FSI & Figure $5 c$ & FSI vs. TSI-Med & $y=-0.104 x+9.347$ & 0.73 & $<0.001$ \\
\hline
\end{tabular}

3.2.3. Testing the Indices with the Same List of Indicator Species for All Indices (Homogenised List)

In order to eliminate the effect of different species assignments in the three investigated methods, and to only focus on the effect of the different calculations, we then used for all three indices the list of ecological species assignments from Jorissen et al. [21]. For FSI, as before, we recalculated species proportions after withdrawing all unassigned and indifferent species from the data set. For Foram-AMBI, the same procedure was followed for unassigned taxa.

The recalculated indices using this homogenised species list are presented in Figure 4. Not surprisingly, all bivariate correlations between the three indices are again significant, and the coefficients of determination have considerably increased (Figure 4), from 0.76 to 0.94 for Foram-AMBI versus FSI, from 0.31 to 0.57 for TSI-Med versus Foram-AMBI, and from 0.28 to 0.58 for TSI-Med versus FSI. This indicates that a substantial part of the scatter around the regression lines in Figure 3 is due to different species assignments rather than to the different methods of the three indices. The difference with the previous version is especially striking for TSI-Med versus FSI (Figure 3b). In fact, TSI-Med values substantially increased when the homogenised list of ecological assessments was used, although we calculated a new reference curve considering the new list of stress-tolerant taxa (Figure S2.1b). This overall increase in TSI-Med values is due to the larger number of species assigned as stress-tolerant when using the list of Jorissen et al. [21].
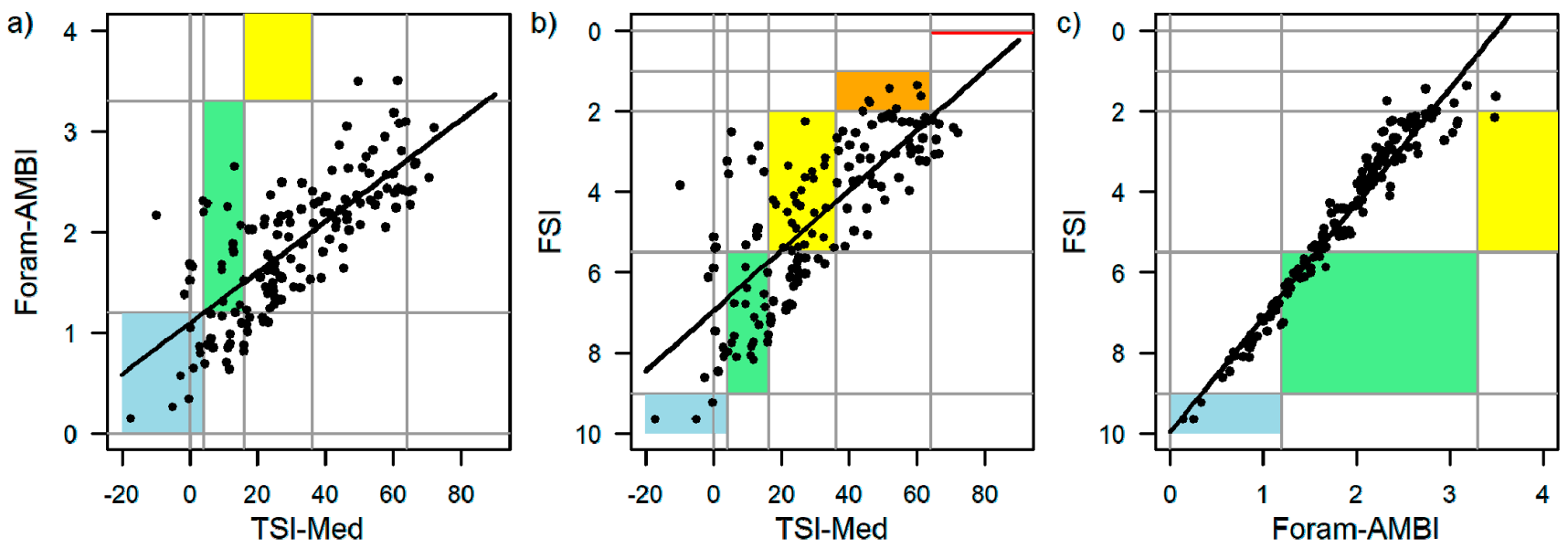

Figure 4. Quality indices based on homogenised groups of indicator species (i.e. Foram-AMBI assignment, [21]) compared two by two. (a) Foram-AMBI vs. TSI-Med, (b) FSI vs. TSI-Med, (c) FSI vs. Foram-AMBI. Information on linear regressions is summarised in Table 4. The grey horizontal and vertical lines represent the Ecological Quality Status limits presented in Table 1. Coloured rectangles correspond to the areas were both indices have the same EQS: blue, "very good"; green, "good"; yellow, "moderate"; orange, "poor" and red, "bad". The scale for FSI is reverse so that the environmental qual-ity scale is in the same direction for each index. 
In TSI-Med, only stress-tolerant taxa are quantified, which makes this index easy to apply, as the percentage of a limited number of taxa in the total assemblage needs to be determined. In Foram-AMBI, the distinction of five different EGs could result in a more sensitive index, however more effort and knowledge are required to classify the species, and misclassification may occur more easily. For FSI, in our opinion, a subdivision into only two extreme groups is not realistic, since many species are neither stress-sensitive nor stress-tolerant.

\subsection{Corrections for the Natural Trophic State}

The TSI-Med is the only index that includes an environmental parameter (\%grains < $63 \mu \mathrm{m})$, which aims to correct for the natural trophic state.

Figure 5a shows the same correlation between TSI-Med and Foram-AMBI as previously shown in Figure $4 \mathrm{a}$, but superposed on this, the coloured background gradient re-presents the percentage of sediment grains $<63 \mu \mathrm{m}$. It appears that samples with a high proportion of grains $<63 \mu \mathrm{m}$ tend to have a high Foram-AMBI value compared to TSI-Med, whereas samples with a low proportion of $<63 \mu \mathrm{m}$ grains show the inverse pattern (high TSI-Med versus low Foram-AMBI). This means that the scatter around the regression line is largely determined by the grain size of the sampled sites, which in our opinion reflects the natural trophic status. In fact, TSI-Med lowers the index value in case of a high proportion of grains $<63 \mu \mathrm{m}$, assuming that such samples represent naturally eutrophic conditions, whereas Foram-AMBI does not apply such a correction.
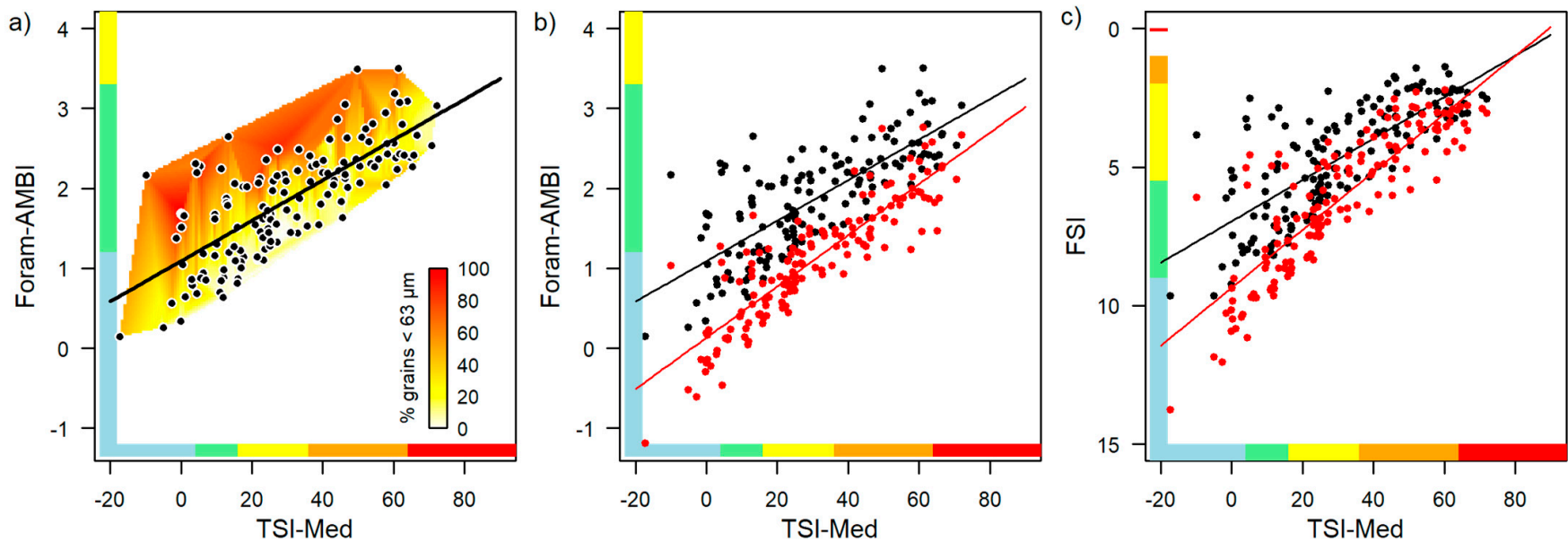

Figure 5. (a) Foram-AMBI as function of TSI-Med, (see Table 4 for regression line). (b) Foram-AMBI and TSI-Med. (c) FSI and TSI-Med. Black and red dots are the indices based on the homogenised list of indicator species (i.e. Foram-AMBI assign-ment [21]). In addition, red dots represent the grain size corrected Foram-AMBI and FSI as a function of TSI-Med. Black and red lines are the regression lines, see Table 4 for regression parameters. Coloured rectangles on the borders represent the EQS: blue, "very good"; green, "good"; yellow, "moderate"; orange, "poor" and red, "bad". The scale for FSI is re-verse so that the environmental quality scale is in the same direction for each index.

In order to have a better idea about the importance of this correction, we tested the possibility to include such a correction for Foram-AMBI and FSI as well. We used the homogenised list of indicator species (based on Jorissen et al. [21]) to exclude the impact of different species assignments, as described in Section 3.2.3. The same methodology as for TSI-Med was used to define the reference curves (see Section 2.3.1 and Figure S2.1 for more details) and calculate the corrected Foram-AMBI (ForamAMBI ${ }_{\text {corrected }}$ ) and the

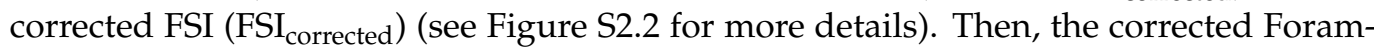

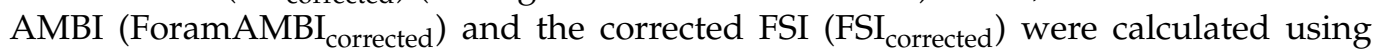
Equations (7) and (8), respectively.

$$
\text { ForamAMBI }{ }_{\text {corrected }}=\frac{\left(\text { ForamAMBI }- \text { ForamAMBI }_{\text {ref }}\right)}{\left(6-\text { ForamAMBI }_{\text {ref }}\right)} \times 6
$$




$$
\mathrm{FSI}_{\text {corrected }}=\frac{\mathrm{FSI}}{\mathrm{FSI}_{\text {ref }}} \times 10
$$

In Figure 5b, we compare both the corrected (red dots) and uncorrected (black dots) Foram-AMBI values with the TSI-Med values. The corrected Foram-AMBI values are systematically much lower, indicating a better environmental quality (Figure 5b), and the scatter around the regression line is highly reduced, leading to an increase in $\mathrm{R}^{2}$ from 0.57 to 0.79 .

Next, we applied the same procedure to FSI. In Figure $5 c$, both the uncorrected (black dots) and corrected (red dots) FSI values are plotted against TSI-Med. The FSI values strongly increase, indicating a better environmental quality; the attributed EQS classes have become much more realistic. The scatter is also reduced, $\mathrm{R}^{2}$ decreased from 0.58 (non-corrected FSI) to 0.73 (corrected FSI), see Since TSI-Med and Foram-AMBI are both largely based on the percentage of stress-tolerant taxa, the rather poor fit is somewhat surprising (Figure 3a). This appears to be mainly the consequence of the very large scatter in Foram-AMBI for samples with high environmental quality. The coefficient of determination between TSI-Med and FSI is even weaker. In Figure $3 b$, we see that this low $R^{2}(0.28)$ is largely due to the fact that samples with a low TSI-Med value (low percentage of stresstolerant taxa, indicative of good quality) cover the whole range of FSI values. This implies that such samples have highly variable percentages of stress-sensitive taxa, which largely (for 91\%) determine the FSI value. On the contrary, the correlation coefficient between FSI and Foram-AMBI (Figure 3c) is much higher (0.69), probably because stress-sensitive taxa also contribute substantially to the Foram-AMBI value.

In conclusion, it appears that when a correction for sediment grain size (as a proxy of the natural trophic state) is applied to Foram-AMBI and FSI, their values shift toward higher-quality values, indicative of better environmental quality. This correction substantially improves their correlation with TSI-Med and seems to yield much more realistic EQS values. Consequently, we strongly recommend including a correction for the natural trophic state when using these indices, following the procedure used for TSI-Med [20]. This is all the more important for regions with important variability of sediment grain size.

\subsection{Proposition of New EQS Class Limits for the Foram-AMBI}

The Ecological Quality Status (EQS) represents the final quantitative evaluation of environmental quality (ranging from "very good" to "bad"). To determine the appropriate EQS category, for each biotic index, the range of values is divided into five classes. In this context, the precise definition of the limits between the EQS categories is crucial. For all three biotic indices, these class limits appear to have been largely based on expert knowledge. When comparing the EQS obtained with the three indices (Figure 3), Foram-AMBI places $99 \%$ of the sites in the classes "very good" and "good"; TSI-Med, 80\%, whereas FSI attributes only $48 \%$ of the samples to these two classes (Table 5). For the present study, we used the EQS class limits as proposed by Barras and Jorissen [53] for TSI-Med, and by Dimiza et al. [23] for FSI (Table 1). For Foram-AMBI, we used the limits proposed for macrofaunal AMBI by Borja et al. [54] (Table 1). These macrofaunal EQS limits were also used in previous foraminiferal studies using Foram-AMBI (e.g., [28,31,34,68]). In these previous studies as in the present one, the EQS based on Foram-AMBI systematically overestimate the ecological quality compared to the other foraminiferal biotic indices (i.e., it gives higher quality status). Therefore, the utilisation of macrofaunal EQS limits on foraminiferal faunas is not adapted and specific EQS limits have to be defined for foraminifera.

Since the need for Foram-AMBI EQS limits adapted for foraminiferal dataset is in our opinion crucial, we propose here a series of preliminary new EQS limits, based on expert knowledge. We expect that in the future, as more data become available, these limits may need to be slightly corrected. 
Table 5. Percentages of sites assigned to each EQS classes by the three biotic indices based on groups of indicator species (TSI-Med, Foram-AMBI, and FSI).

\begin{tabular}{|c|c|c|c|c|c|c|}
\hline Condition & Index & Very Good & Good & Moderate & Poor & Bad \\
\hline \multirow{3}{*}{$\begin{array}{l}\text { Original indices } \\
\text { (Section 3.2.2) }\end{array}$} & TSI-Med & 36.1 & 44.2 & 16.3 & 3.4 & 0.0 \\
\hline & Foram-AMBI & 20.4 & 78.2 & 1.4 & 0.0 & 0.0 \\
\hline & FSI & 3.4 & 44.2 & 50.3 & \multicolumn{2}{|c|}{2.0} \\
\hline \multirow{3}{*}{$\begin{array}{l}\text { Modified indices as in Section } 3.2 .3 \\
\text { (homogenised list) }\end{array}$} & TSI-Med & 9.5 & 19.7 & 32.0 & 34.0 & 4.8 \\
\hline & Foram-AMBI & \multicolumn{5}{|c|}{ Same as the original index (Section 3.2.2) } \\
\hline & FSI & 2.0 & 32.0 & 61.9 & & \\
\hline \multirow{3}{*}{$\begin{array}{l}\text { Modified indices as in Section } 3.3 \\
\text { (homogenised list + grain size correction) }\end{array}$} & TSI-Med & \multicolumn{5}{|c|}{ Same as the index with the homogenised list (Section 3.2.3) } \\
\hline & Foram-AMBI & 66.7 & 33.3 & 0.0 & 0.0 & 0.0 \\
\hline & FSI & 15.6 & 38.1 & 46.3 & \multicolumn{2}{|c|}{0.0} \\
\hline $\begin{array}{l}\text { Original index with proposed EQS class } \\
\text { limits (this study) }\end{array}$ & Foram-AMBI & 26.5 & 52.4 & 19.7 & 1.4 & 0.0 \\
\hline
\end{tabular}

EQS class limits for TSI-Med are close to the expected quality found in our study area, given the size of the region and the diversity of environments: the majority of the stations with very good or good environmental quality, some stations with moderate environmental quality, and only a few stations with the worst environmental quality. Therefore, the proposed new EQS limits for Foram-AMBI have been determined by aiming to obtain the same proportion of samples in each of the five EQS classes as for TSI-Med (using the original species list) (Table 5 and Figure 6). The new EQS limits we propose for the Foram-AMBI are as follows: very good: $0 \leq \mathrm{x}<1.4$; good: $1.4 \leq \mathrm{x}<2.4$; moderate: $2.4 \leq \mathrm{x}<3.4$; poor: $3.4 \leq \mathrm{x}<4.4$; bad: $4.4 \leq \mathrm{x} \leq 6$. As expected, the new Foram-AMBI EQS class limits are substantially lower than the one for macrofauna, especially towards bad environmental quality (Table 1).
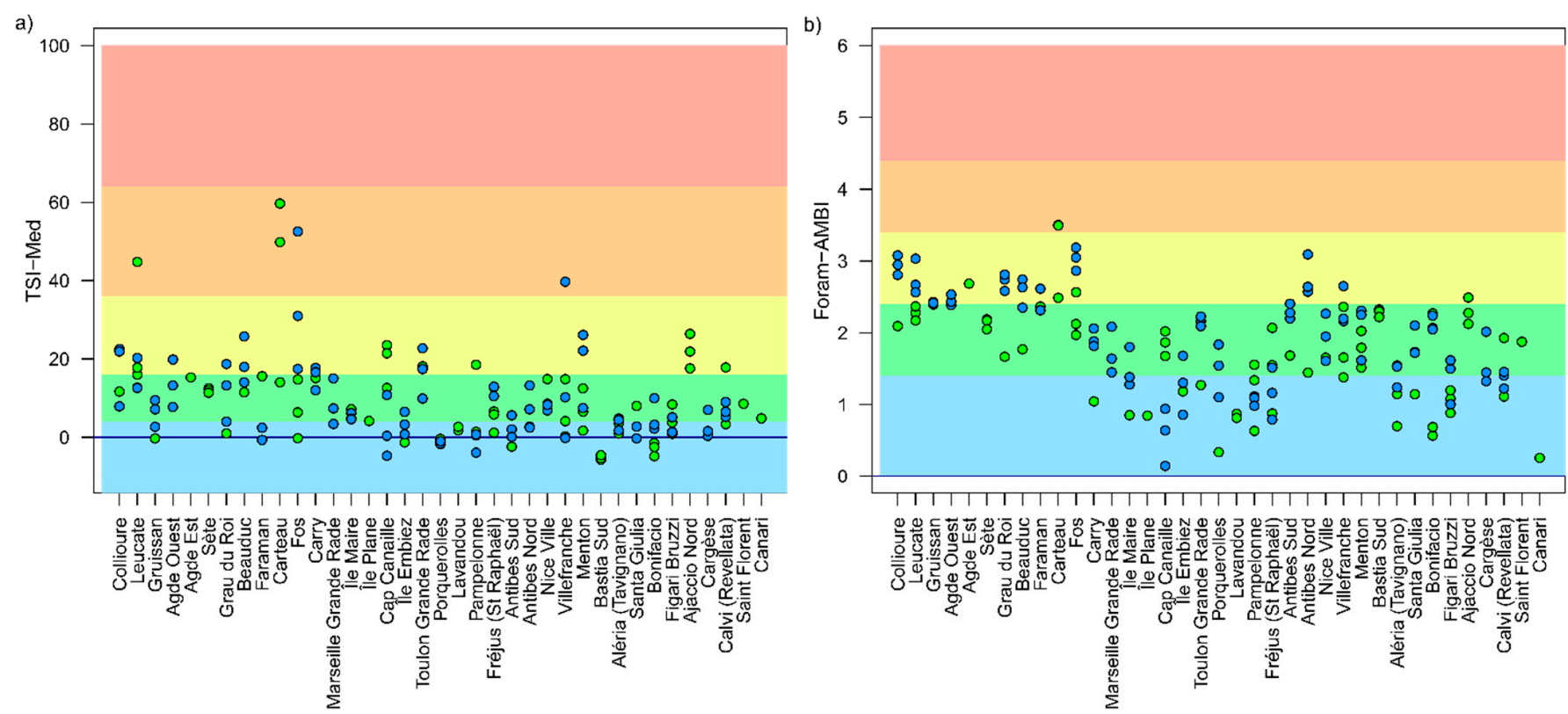

Figure 6. (a) TSI-Med and (b) Foram-AMBI values at each station. Both indices are calculated as they were described in their original descriptions. Green dots: sampled in 2012, and blues dots: sampled in 2015. EQS are represented by the coloured background: blue, "very good"; green, "good"; yellow, "moderate"; orange, "poor"; and red, "bad". For the TSI-Med, EQS classes limits are from Barras and Jorissen [53], and for Foram-AMBI they are proposed in this study. 


\section{Conclusions and Recommendations}

We compared four quality indices based on living (Rose Bengal-stained) foraminiferal faunas that evaluate the environmental quality due to organic matter enrichment and its associated oxygen depletion. These indices are based on two different approaches, species diversity and groups of indicator species. Here, we present several recommendations concerning the use of these four indices to assess the environmental quality in subtidal coastal Mediterranean environments. These recommendations are graphically summarised in Figure 7.

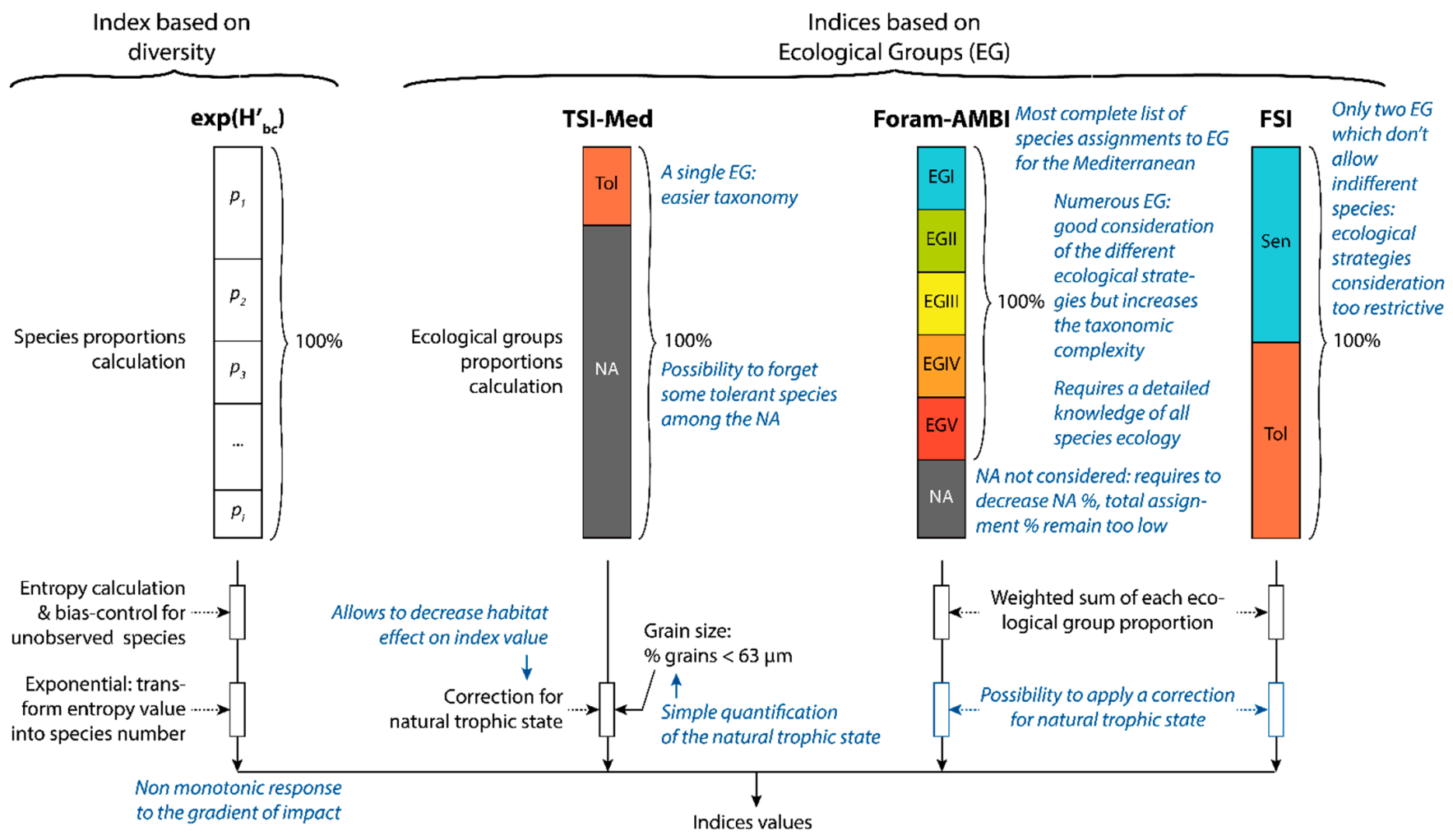

Figure 7. Calculation of the diversity-based index, $\exp \left(\mathrm{H}_{\mathrm{bc}}^{\prime}\right)$, and the three indices based on Ecological Groups (EG): TSI-Med, Foram-AMBI and FSI. Italic blue text: recommendations from this study. $100 \%$ represent the fauna included in the EG proportions calculation. $p_{1}, p_{2}, p_{3}$ to $p_{i}$ : proportions from the 1 st to the $i$ th species. EGI to EGV: Ecological Groups: sensitive, indifferent, 3rd order opportunist, 2nd order opportunist, and 1st order opportunist. Sen: stress-sensitive species and Tol: stress-tolerant species. NA: Not-Assigned species.

$\operatorname{Exp}\left(\mathrm{H}_{\mathrm{bc}}^{\prime}\right)$, based on diversity, shows a non-monotonic relation with other quality indices, suggesting that the index does not have a monotonic relation with the gradient of impact. Therefore, we do not recommend the use of a diversity-based index in coastal open marine soft-bottom environments of the Mediterranean.

The three foraminiferal indices based on groups of indicator species present some important differences: only TSI-Med includes a correction for the natural trophic state; TSI-Med and FSI are based on the entire assemblage, whereas Foram-AMBI is based on a reduced data-set, using only assigned and/or indicator taxa; the index value of TSI-Med and Foram-AMBI is mainly determined by stress-tolerant taxa, whereas the index value of FSI is largely determined by the frequency of stress-sensitive taxa. In view of these differences, it is reassuring that these three methods yield comparable results.

Our tests further show that the list of species assignments to ecological categories largely influences the precise index values. For this reason, it appears essential that all methods use the same list of assignments. For the Mediterranean Sea, we recommend the use of the list proposed by Jorissen et al. [21], because it is rather exhaustive, and is based on an objective analysis of a large number of quantitative studies. However, the 
absence of many taxa on this list strongly decreases the reliability of the indices and should be addressed urgently.

TSI-Med and Foram-AMBI are mostly based on stress-tolerant species whereas FSI is largely dependent on stress-sensitive species. Both methods yield similar results, which are significantly correlated. We have not found any objective indications that one of these indices performs better than the other two. However, for reasons of parsimony, it seems preferable to use the simplest available index. This criterion would favour the TSI-Med, which uses a limited number of categories and indicator species, rather than Foram-AMBI and FSI, in which all taxa are considered, which requires a much more extensive taxonomical knowledge from the operator.

The treatment of unassigned species strongly influences the results of each index. Because the ecological strategy of these species is mostly unknown, for FSI and ForamAMBI, which include all species, it seems preferable to exclude them from the data set and to recalculate percentages afterwards. However, the rate of the considered assigned species must remain high $(>80 \%)$ for meaningful results, as the quality assessment will rely on it.

According to the Water Framework Directive [69] or the Marine Strategy Framework Directive [70], the EQS should take into account reference conditions. The definition of natural trophic state background is especially important for study areas with contrasted sedimentological and hydrodynamic conditions [14,29]. Indeed, A sensible characterisation of an environment can only be made when the natural (baseline) conditions are taken into account. At present, only the TSI-Med index directly includes this aspect, as a correction for the natural trophic state, and for this reason, it has our preference. However, as we have shown, it is possible to incorporate a similar correction in the FSI or Foram-AMBI indices as well.

The transfer from an index value to an environmental quality is necessary in biomonitoring studies. This process goes through the definition of EQS classes, separated by limits. The limits currently used for the Foram-AMBI in foraminiferal studies are those defined for macrofauna, which are not adapted. Therefore, we recommend the use of new EQS limits for the Foram-AMBI in the Mediterranean open waters: very good: $0 \leq x<1.4$; good: $1.4 \leq \mathrm{x}<2.4$; moderate: $2.4 \leq \mathrm{x}<3.4$; poor: $3.4 \leq \mathrm{x}<4.4 ;$ bad: $4.4 \leq \mathrm{x} \leq 6$.

Supplementary Materials: The following are available online at https:/ / www.mdpi.com/article/10 $.3390 /$ w13223193/s1, Table S1: Details on sampled stations. Figure S2: reference curves used in the corrections for the natural trophic state. Table S3: Species assignment for the biotic indices based on groups of indicator species (TSI-Med, Foram-AMBI, and FSI). Species listed in Table S3 correspond to the species assigned in this study, and they do not correspond to a complete list of all species assigned by each biotic index. Table S4: Indices regression models including only samples with less than $20 \%$ unassigned species.

Author Contributions: Conceptualization, B.P., C.B. and F.J.J; methodology, G.M.M.; validation, B.P., C.B. and F.J.J; formal analysis, B.P.; investigation, B.P., C.B., E.B., L.M.C., C.C., É.B., G.M.M. and F.J.J.; resources, G.M.M.; data curation, B.P., C.B.; writing—original draft preparation, B.P.; writing-review and editing, B.P., C.B., E.B., L.M.C., C.C., G.M.M. and F.J.J.; visualization, B.P.; supervision, C.B. and F.J.J.; project administration, C.B. and F.J.J; funding acquisition, C.B. and F.J.J. All authors have read and agreed to the published version of the manuscript.

Funding: This research and the APC were funded by the Agence de l'Eau Rhône Méditerranée Corse.

Data Availability Statement: Data supporting this research can be found online on Pangaea: DOI in progress. The data include foraminiferal fauna counts and grain size data.

Acknowledgments: The authors thank the Agence de l'Eau Rhône Méditerranée Corse, especially Pierre Boissery, for funding this study. We are thankful to Ifremer, especially Bruno Andral, and the RV Europe crew members for the sampling surveys. We are also grateful to Sophie Quinchard, Élodie Poux, Jérôme Jolain, Clémence Caulle (OceanZoom), and Charlotte LeKieffre for their help in the sample treatment. We are grateful to the editor and the two anonymous reviewers who helped improving the quality of the manuscript. 
Conflicts of Interest: The authors declare no conflict of interest. The funders had no role in the design of the study; in the interpretation of data; in the writing of the manuscript, or in the decision to publish the results.

\section{References}

1. Zeppilli, D.; Sarrazin, J.; Leduc, D.; Arbizu, P.M.; Fontaneto, D.; Fontanier, C.; Gooday, A.J.; Kristensen, R.M.; Ivanenko, V.N.; Sørensen, M.V.; et al. Is the Meiofauna a Good Indicator for Climate Change and Anthropogenic Impacts? Mar. Biodivers. 2015, 45, 505-535. [CrossRef]

2. Francescangeli, F.; Quijada, M.; Armynot du Châtelet, E.; Frontalini, F.; Trentesaux, A.; Billon, G.; Bouchet, V.M.P. Multidisciplinary Study to Monitor Consequences of Pollution on Intertidal Benthic Ecosystems (Hauts de France, English Channel, France): Comparison with Natural Areas. Mar. Environ. Res. 2020, 160, 105034. [CrossRef]

3. Frontalini, F.; Coccioni, R. Benthic Foraminifera as Bioindicators of Pollution: A Review of Italian Research over the Last Three Decades. Rev. Micropaléontol. 2011, 54, 115-127. [CrossRef]

4. Mojtahid, M.; Jorissen, F.J.; Durrieu, J.; Galgani, F.; Howa, H.; Redois, F.; Camps, R. Benthic Foraminifera as Bio-Indicators of Drill Cutting Disposal in Tropical East Atlantic Outer Shelf Environments. Mar. Micropaleontol. 2006, 61, 58-75. [CrossRef]

5. Mojtahid, M.; Jorissen, F.J.; Pearson, T.H. Comparison of Benthic Foraminiferal and Macrofaunal Responses to Organic Pollution in the Firth of Clyde (Scotland). Mar. Pollut. Bull. 2008, 56, 42-76. [CrossRef]

6. Pearson, T.H.; Rosenberg, R. Macrobenthic Succession in Relation to Organic Enrichment and Pollution of the Marine Environment. Oceanogr. Mar. Biol. Annu. Rev. 1978, 16, 229-311.

7. Jorissen, F.J.; De Stigter, H.; Widmark, J.G.V. A Conceptual Model Explaining Benthic Foraminiferal Microhabitats. Mar. Micropaleontol. 1995, 26, 3-15. [CrossRef]

8. Jorissen, F.J. Benthic foraminiferal microhabitats below the sediment-water interface. In Modern Foraminifera; Springer: Dordrecht, The Netherlands, 1999; pp. 161-179. ISBN 978-0-412-82430-2.

9. Nilsson, H.C.; Rosenberg, R. Succession in Marine Benthic Habitats and Fauna in Response to Oxygen Deficiency: Analysed by Sediment Profile-Imaging and by Grab Samples. Mar. Ecol. Prog. Ser. 2000, 197, 139-149. [CrossRef]

10. Puente, A.; Diaz, R.J. Response of Benthos to Ocean Outfall Discharges: Does a General Pattern Exist? Mar. Pollut. Bull. 2015, 101, 174-181. [CrossRef]

11. Borja, Á.; Franco, J.; Pérez, V. A Marine Biotic Index to Establish the Ecological Quality of Soft-Bottom Benthos within European Estuarine and Coastal Environments. Mar. Pollut. Bull. 2000, 40, 1100-1114. [CrossRef]

12. Simboura, N.; Zenetos, A. Benthic Indicators to Use in Ecological Quality Classification of Mediterranean Soft Bottom Marine Ecosystems, Including a New Biotic Index. Mediterr. Mar. Sci. 2002, 3/2, 77-111. [CrossRef]

13. Rosenberg, R.; Blomqvist, M.; Nilsson, H.C.; Cederwall, H.; Dimming, A. Marine Quality Assessment by Use of Benthic SpeciesAbundance Distributions: A Proposed New Protocol within the European Union Water Framework Directive. Mar. Pollut. Bull. 2004, 49, 728-739. [CrossRef] [PubMed]

14. Muxika, I.; Borja, Á.; Bald, J. Using Historical Data, Expert Judgement and Multivariate Analysis in Assessing Reference Conditions and Benthic Ecological Status, According to the European Water Framework Directive. Mar. Pollut. Bull. 2007, 55, 16-29. [CrossRef] [PubMed]

15. Gobert, S.; Sartoretto, S.; Rico-Raimondino, V.; Andral, B.; Chery, A.; Lejeune, P.; Boissery, P. Assessment of the Ecological Status of Mediterranean French Coastal Waters as Required by the Water Framework Directive Using the Posidonia Oceanica Rapid Easy Index: PREI. Mar. Pollut. Bull. 2009, 58, 1727-1733. [CrossRef]

16. Alve, E.; Lepland, A.; Magnusson, J.; Backer-Owe, K. Monitoring Strategies for Re-Establishment of Ecological Reference Conditions: Possibilities and Limitations. Mar. Pollut. Bull. 2009, 59, 297-310. [CrossRef]

17. Dolven, J.K.; Alve, E.; Rygg, B.; Magnusson, J. Defining Past Ecological Status and in Situ Reference Conditions Using Benthic Foraminifera: A Case Study from the Oslofjord, Norway. Ecol. Indic. 2013, 29, 219-233. [CrossRef]

18. Francescangeli, F.; Armynot du Chatelet, E.; Billon, G.; Trentesaux, A.; Bouchet, V.M.P. Palaeo-Ecological Quality Status Based on Foraminifera of Boulogne-Sur-Mer Harbour (Pas-de-Calais, Northeastern France) over the Last 200 Years. Mar. Environ. Res. 2016, 117, 32-43. [CrossRef] [PubMed]

19. O'Brien, P.A.J.; Polovodova Asteman, I.; Bouchet, V.M.P. Benthic Foraminiferal Indices and Environmental Quality Assessment of Transitional Waters: A Review of Current Challenges and Future Research Perspectives. Water 2021, 13, 1898. [CrossRef]

20. Barras, C.; Jorissen, F.J.; Labrune, C.; Andral, B.; Boissery, P. Live Benthic Foraminiferal Faunas from the French Mediterranean Coast: Towards a New Biotic Index of Environmental Quality. Ecol. Indic. 2014, 36, 719-743. [CrossRef]

21. Jorissen, F.J.; Nardelli, M.P.; Almogi-Labin, A.; Barras, C.; Bergamin, L.; Bicchi, E.; El Kateb, A.; Ferraro, L.; McGann, M.; Morigi, C.; et al. Developing Foram-AMBI for Biomonitoring in the Mediterranean: Species Assignments to Ecological Categories. Mar. Micropaleontol. 2018, 140, 33-45. [CrossRef]

22. Bouchet, V.M.P.; Frontalini, F.; Francescangeli, F.; Sauriau, P.-G.; Geslin, E.; Martins, M.V.A.; Almogi-Labin, A.; Avnaim-Katav, S.; Di Bella, L.; Cearreta, A.; et al. Indicative Value of Benthic Foraminifera for Biomonitoring: Assignment to Ecological Groups of Sensitivity to Total Organic Carbon of Species from European Intertidal Areas and Transitional Waters. Mar. Pollut. Bull. 2021, 164, 112071. [CrossRef] 
23. Dimiza, M.D.; Triantaphyllou, M.V.; Koukousioura, O.; Hallock, P.; Simboura, N.; Karageorgis, A.P.; Papathanasiou, E. The Foram Stress Index: A New Tool for Environmental Assessment of Soft-Bottom Environments Using Benthic Foraminifera. A Case Study from the Saronikos Gulf, Greece, Eastern Mediterranean. Ecol. Indic. 2016, 60, 611-621. [CrossRef]

24. Hill, M.O. Diversity and Evenness: A Unifying Notation and Its Consequences. Ecology 1973, 54, 427-432. [CrossRef]

25. Chao, A.; Tsung-Jen, S. Nonparametric Estimation of Shannon's Index of Diversity When There Are Unseen Species in Sample. Environ. Ecol. Stat. 2003, 10, 429-443. [CrossRef]

26. Bouchet, V.M.P.; Alve, E.; Rygg, B.; Telford, R.J. Benthic Foraminifera Provide a Promising Tool for Ecological Quality Assessment of Marine Waters. Ecol. Indic. 2012, 23, 66-75. [CrossRef]

27. Bouchet, V.M.P.; Goberville, E.; Frontalini, F. Benthic Foraminifera to Assess Ecological Quality Statuses in Italian Transitional Waters. Ecol. Indic. 2018, 84, 130-139. [CrossRef]

28. El Kateb, A.; Stalder, C.; Martínez-Colón, M.; Mateu-Vicens, G.; Francescangeli, F.; Coletti, G.; Stainbank, S.; Spezzaferri, S. Foraminiferal-Based Biotic Indices to Assess the Ecological Quality Status of the Gulf of Gabes (Tunisia): Present Limitations and Future Perspectives. Ecol. Indic. 2020, 111, 105962. [CrossRef]

29. Borja, Á.; Dauer, D.M.; Grémare, A. The Importance of Setting Targets and Reference Conditions in Assessing Marine Ecosystem Quality. Ecol. Indic. 2012, 12, 1-7. [CrossRef]

30. Alve, E.; Hess, S.; Bouchet, V.M.P.; Dolven, J.K.; Rygg, B. Intercalibration of Benthic Foraminiferal and Macrofaunal Biotic Indices: An Example from the Norwegian Skagerrak Coast (NE North Sea). Ecol. Indic. 2019, 96, 107-115. [CrossRef]

31. Fossile, E.; Sabbatini, A.; Spagnoli, F.; Caridi, F.; Dell'Anno, A.; de Marco, R.; Dinelli, E.; Droghini, E.; Tramontana, M.; Negri, A. Sensitivity of Foraminiferal-Based Indices to Evaluate the Ecological Quality Status of Marine Coastal Benthic Systems: A Case Study of the Gulf of Manfredonia (Southern Adriatic Sea). Mar. Pollut. Bull. 2021, 163, 111933. [CrossRef] [PubMed]

32. Damak, M.; Fourati, R.; Elleuch, B.; Kallel, M. Environmental Quality Assessment of the Fish Farms' Impact in the Monastir Bay (Eastern of Tunisia, Central Mediterranean): A Benthic Foraminiferal Perspective. Environ. Sci. Pollut. Res. 2020, 27, 9059-9074. [CrossRef] [PubMed]

33. Musco, M.; Cuttitta, A.; Bicchi, E.; Quinci, E.M.; Sprovieri, M.; Tranchida, G.; Giaramita, L.; Traina, A.; Salvagio Manta, D.; Gherardi, S.; et al. Benthic Foraminifera as Bio-Indicators of Anthropogenic Impacts in Coastal Environments: Acqua Dei Corsari Area Case Study (Palermo, Italy). Mar. Pollut. Bull. 2017, 117, 75-87. [CrossRef] [PubMed]

34. Parent, B.; Hyams-Kaphzan, O.; Barras, C.; Lubinevsky, H.; Jorissen, F.J. Testing Foraminiferal Environmental Quality Indices along a Well-Defined Organic Matter Gradient in the Eastern Mediterranean. Ecol. Indic. 2021, 125, 107498. [CrossRef]

35. Schönfeld, J.; Alve, E.; Geslin, E.; Jorissen, F.; Korsun, S.; Spezzaferri, S. The FOBIMO (FOraminiferal BIo-MOnitoring) InitiativeTowards a Standardised Protocol for Soft-Bottom Benthic Foraminiferal Monitoring Studies. Mar. Micropaleontol. 2012, 94-95, 1-13. [CrossRef]

36. Parent, B.; Barras, C.; Jorissen, F. An Optimised Method to Concentrate Living (Rose Bengal-Stained) Benthic Foraminifera from Sandy Sediments by High Density Liquids. Mar. Micropaleontol. 2018, 144, 1-13. [CrossRef]

37. R Core Team. R: A Language and Environment for Statistical Computing; R Foundation for Statistical Computing: Vienna, Austria, 2021.

38. Savicky, P. Spearman's Rank Correlation Test. 2014. Available online: https://CRAN.R-project.org/package=pspearman (accessed on 10 November 2021).

39. Weston, D. Quantitative Examination of Macrobenthic Community Changes along an Organic Enrichment Gradient. Mar. Ecol. Prog. Ser. 1990, 61, 233-244. [CrossRef]

40. Alve, E. Benthic Foraminiferal Responses to Estuarine Pollution: A Review. J. Foraminifer. Res. 1995, 25, 190-2003. [CrossRef]

41. Shannon, C.E. A Mathematical Theory of Communication. Bell Syst. Tech. J. 1948, 27, 379-423. [CrossRef]

42. Hausser, J.; Strimmer, K. Entropy Inference and the James-Stein Estimator, with Application to Nonlinear Gene Association Networks. J. Mach. Learn. Res. 2009, 10, 1469-1484.

43. Bock, M.J.; Mayer, L.M. Mesodensity Organo-Clay Associations in a near-Shore Sediment. Mar. Geol. 2000, 163, 65-75. [CrossRef]

44. Hedges, J.I.; Keil, R.G.; Cowie, G.L. Sedimentary Diagenesis: Organic Perspectives with Inorganic Overlays. Chem. Geol. 1993, 107, 487-492. [CrossRef]

45. Jorissen, F.J. The Distribution of Benthic Foraminifera in the Adriatic Sea. Mar. Micropaleontol. 1987, 12, 21-48. [CrossRef]

46. Jarvis, A.; Reuter, H.I.; Nelson, A.; Guevara, E. Hole-Filled SRTM for the Globe Version 4, Available from the CGIAR-CSI SRTM 90m Database. Available online: http:/ / srtm.csi.cgiar.org (accessed on 30 April 2021).

47. Marine Information Service EMODnet Digital Bathymetry (DTM). 2016. Available online: https://doi.org/10.12770/c7b53704-9 99d-4721-b1a3-04ec60c87238 (accessed on 13 March 2021).

48. Alve, E.; Korsun, S.; Schönfeld, J.; Dijkstra, N.; Golikova, E.; Hess, S.; Husum, K.; Panieri, G. Foram-AMBI: A Sensitivity Index Based on Benthic Foraminiferal Faunas from North-East Atlantic and Arctic Fjords, Continental Shelves and Slopes. Mar. Micropaleontol. 2016, 122, 1-12. [CrossRef]

49. O’Malley, B.J.; Schwing, P.T.; Martínez-Colón, M.; Spezzaferri, S.; Machain-Castillo, M.L.; Larson, R.A.; Brooks, G.R.; RuizFernández, A.C.; Hollander, D.J. Development of a Benthic Foraminifera Based Marine Biotic Index (Foram-AMBI) for the Gulf of Mexico: A Decision Support Tool. Ecol. Indic. 2021, 120, 106916. [CrossRef]

50. Borja, Á.; Mader, J.; Muxika, I. Instructions for the Use of the AMBI Index Software (Version 5.0). Rev. Investig. Mar. 2012, 19, 71-82. 
51. Triantaphyllou, M.V.; (Department of Historical Geology-Paleontology, Faculty of Geology, National and Kapodistrian University of Athens, Panepistimioupolis 157 84, Athens, Greece). Personal communication, 2019.

52. Hallock, P.; (College of Marine Science, University of South Florida, Saint Petersburg, FL 33701, USA). Personal communication, 2019.

53. Barras, C.; Jorissen, F.J. Étude des Faunes de Foraminifères Benthiques de la Côte Méditerranéenne Française: Mise en Place d’un Nouvel indice Biotique Dans le Cadre de Directive Cadre Eau-Campagne DCE 2009; Laboratoire des Bio-Indicateurs Actuels et Fossiles (BIAF) Université d'Angers: Angers, France, 2011; p. 162.

54. Borja, A.; Muxika, I.; Franco, J. The Application of a Marine Biotic Index to Different Impact Sources Affecting Soft-Bottom Benthic Communities along European Coasts. Mar. Pollut. Bull. 2003, 46, 835-845. [CrossRef]

55. Grémare, A.; Labrune, C.; Vanden Berghe, E.; Amouroux, J.; Bachelet, G.; Zettler, M.; Vanaverbeke, J.; Fleischer, D.; Bigot, L.; Maire, O.; et al. Comparison of the Performances of Two Biotic Indices Based on the MacroBen Database. Mar. Ecol. Prog. Ser. 2009, 382, 297-311. [CrossRef]

56. Martínez-Crego, B.; Alcoverro, T.; Romero, J. Biotic Indices for Assessing the Status of Coastal Waters: A Review of Strengths and Weaknesses. J. Environ. Monit. 2010, 12, 1013-1028. [CrossRef] [PubMed]

57. Zettler, M.L.; Proffitt, C.E.; Darr, A.; Degraer, S.; Devriese, L.; Greathead, C.; Kotta, J.; Magni, P.; Martin, G.; Reiss, H.; et al. On the Myths of Indicator Species: Issues and Further Consideration in the Use of Static Concepts for Ecological Applications. PLoS ONE 2013, 8, e78219. [CrossRef]

58. Gillett, D.J.; Weisberg, S.B.; Grayson, T.; Hamilton, A.; Hansen, V.; Leppo, E.W.; Pelletier, M.C.; Borja, A.; Cadien, D.; Dauer, D.; et al. Effect of Ecological Group Classification Schemes on Performance of the AMBI Benthic Index in US Coastal Waters. Ecol. Indic. 2015, 50, 99-107. [CrossRef]

59. Robertson, B.P.; Savage, C.; Gardner, J.P.A.; Robertson, B.M.; Stevens, L.M. Optimising a Widely-Used Coastal Health Index through Quantitative Ecological Group Classifications and Associated Thresholds. Ecol. Indic. 2016, 69, 595-605. [CrossRef]

60. Glémarec, M. Ecological Impact of an Oil Spill: Utilization of Biological Indicators. Water Sci. Technol. 1986, 18, 203-211. [CrossRef]

61. Majeed, S.A. Organic Matter and Biotic Indices on the Beaches of North Brittany. Mar. Pollut. Bull. 1987, 18, 490-495. [CrossRef]

62. Dauvin, J.C.; Andrade, H.; de-la-Ossa-Carretero, J.A.; Del-Pilar-Ruso, Y.; Riera, R. Polychaete/Amphipod Ratios: An Approach to Validating Simple Benthic Indicators. Ecol. Indic. 2016, 63, 89-99. [CrossRef]

63. Subida, M.D.; Drake, P.; Jordana, E.; Mavrič, B.; Pinedo, S.; Simboura, N.; Torres, J.; Salas, F. Response of Different Biotic Indices to Gradients of Organic Enrichment in Mediterranean Coastal Waters: Implications of Non-Monotonic Responses of Diversity Measures. Ecol. Indic. 2012, 19, 106-117. [CrossRef]

64. Borja, Á.; Muxika, I. Guidelines for the Use of AMBI (AZTI's Marine Biotic Index) in the Assessment of the Benthic Ecological Quality. Mar. Pollut. Bull. 2005, 50, 787-789. [CrossRef]

65. Jorissen, F.J. Benthic Foraminifera from the Adriatic Sea: Principles of Phenotypic Variation; Utrecht University: Utrecht, The Netherlands, 1988.

66. Romano, E.; Bergamin, L.; Ausili, A.; Pierfranceschi, G.; Maggi, C.; Sesta, G.; Gabellini, M. The Impact of the Bagnoli Industrial Site (Naples, Italy) on Sea-Bottom Environment. Chemical and Textural Features of Sediments and the Related Response of Benthic Foraminifera. Mar. Pollut. Bull. 2009, 59, 245-256. [CrossRef]

67. Ferraro, L.; Alberico, I.; Lirer, F.; Vallefuoco, M. Distribution of Benthic Foraminifera from the Southern Tyrrhenian Continental Shelf (South Italy). Rendiconti Lincei 2012, 23, 103-119. [CrossRef]

68. Cavaliere, M.; Barrenechea Angeles, I.; Montresor, M.; Bucci, C.; Brocani, L.; Balassi, E.; Margiotta, F.; Francescangeli, F.; Bouchet, V.M.P.; Pawlowski, J.; et al. Assessing the Ecological Quality Status of the Highly Polluted Bagnoli Area (Tyrrhenian Sea, Italy) Using Foraminiferal EDNA Metabarcoding. Sci. Total Environ. 2021, 790, 147871. [CrossRef] [PubMed]

69. European Commission. Directive 2000/60/EC of the European Parliament and of the Council of 23 October 2000 Establishing a Framework for Community Action in the Field of Water Policy. Off. J. Eur. Communities 2000, L 237, 1-72.

70. European Commission. Directive 2008/56/EC of the European Parliament and of the Council of 17 June 2008 Establishing a Framework for Community Action in the Field of Marine Environmental Policy (Marine Strategy Framework Directive). Off. J. Eur. Union 2008, L 164, 19-40. 